\title{
Accuracy of the Most Popular Building Performance Simulation Tools: Experimental comparison for a conventional and a PCM-based Test Box
}

\author{
Domenico Mazzeo ${ }^{1,2}$, Piercarlo Romagnoni ${ }^{1}$, Nicoletta Matera ${ }^{2}$, Giuseppe Oliveti $^{2}$, Cristina \\ Cornaro $^{3}$, Livio De Santoli ${ }^{4}$ \\ ${ }^{1}$ University IUAV of Venice, Department of Design and Planning in Complex Environments \\ ${ }^{2}$ University of Calabria, Department of Mechanical, Energy and Management Engineering \\ ${ }^{3}$ University of Rome Tor Vergata, Department of Enterprise Engineering \\ ${ }^{4}$ University of Rome "La Sapienza", Department of Astronautics, Electrical and Energy \\ Engineering
}

\begin{abstract}
The dynamic thermal simulation has become a recognized instrument to predict building thermal behaviour. Many tools were developed in the last decades, which were independently validated, by considering different operating conditions, and rarely were directly compared in the same conditions. The objective of this work is to evaluate the prediction accuracy of the most popular building performance simulation tools, namely TRNSYS, EnergyPlus and IDA ICE, by means of a comparison of the simulated results and the experimental measurements detected under real operating conditions. For this issue, two different smallscale solar test boxes (STBs) with one glazed wall exposed to the outdoor environment of Rome was employed for the experimental investigation. The envelope of the reference STB is insulated and made by conventional materials. In the other case, the STB floor is equipped also with a commercial phase change material (PCM) panel. The results of this comparison have highlighted the most accurate mathematical models for the prediction of the dynamic thermal behaviour of the STB in the absence and presence of a PCM.
\end{abstract}

\section{Introduction}

The energy intensity per square meter of the global buildings sector needs to improve on average by $30 \%$ by 2030 , compared to 2015 , to be on track to meet global climate ambitions set out in the Paris Agreement (International Energy Agency, 2017). Rapid deployment of energy-efficient and low-carbon solutions and construction for buildings can help put the world on a sustainable trajectory. Some of the technologies needed to transform the buildings sector are already commercially available and cost-effective, with payback periods of less than five years. The potential of these technologies is normally estimated by using Building Performance Simulation (BPS) tools, which has become a key instrument in the evaluation of the building energy demand and thermal comfort. As regards new buildings, they allow a user to design properly the envelope, while in the case of buildings undergoing major renovation permit to identify the most properly interventions to reduce energy needs and improve the indoor thermal comfort. Over the past 50 years, according to the literature review, many dynamic simulation tools were developed (Harish et al., 2016; Saffari et al., 2017). Each BPS tool is based on different mathematical models to describe the three heat transfer mechanisms between the building envelope and the outdoor and indoor environments. Among these, TRaNsient SYstem Simulation 17 (TRNSYS) (University of Wisconsin, 2012), EnergyPlus 8.6 (U.S. Department of Energy's (DOE) Building Technologies Office (BTO), 2016) and IDA Indoor Climate and Energy (ICE) 4.8 (Equa Simulation AB, 2018) are the most widespread. The selected tools have been extensively used for this purpose and were individually validated. However, these validations were obtained for different climatic conditions and buildings. For this reason, it is not possible to make a direct comparison of their prediction with the current findings. In addition, in the last years, new materials were proposed to improve the thermal response of building envelope in the winter and summer period, such as phase change materials (PCMs), green roofs and walls, cool materials, vacuum super insulation materials and so on. For this issue, the abovementioned tools have integrated into own library new simulation subroutines able to predict the thermal response of these innovative materials. In particular, passive cooling and heating by means of PCM application in walls offer high potential to improve the building dynamic and energy performance (Mazzeo et al., 2017) and have attracted the attention of many researchers, for the development of mathematical models (Mazzeo et al., 2018) and companies for the production of PCM-based solutions. For researchers and designers, the BPS tools are fundamental to appropriately characterize and integrate PCM into the building envelope. The simulation subroutines developed by the abovementioned tools employ different mathematical models for PCM thermal behaviour prediction and, consequently, it is necessary to evaluate which approach is the most appropriate. In several studies, these subroutines were validated and extensively used to evaluate the behaviour of PCM in buildings. In particular, IDA ICE PCM tool was 
validated in previous work by employing the same STB used in this research (Cornaro et al., 2015; Cornaro et al., 2017). Instead, Type 1270 of TRNSYS and EnergyPlus PCM tool were validated, respectively, by Jayalath et al. (2016) and Panayiotou et al. (2016), and by Tabares-Velasco et al. (2012). All tools have shown a good agreement with the experimental data despite the different assumptions. However, the previous researches were conducted considering real operating conditions in an outdoor environment or thermally controlled test boxes. Consequently, nonetheless the large employment of BPS tools, there is a gap in the knowledge of the result accuracy provided by the different models in the same conditions. The developed research aims to evaluate the effect produced by the different building simulation models implemented in the different BPS tools and to identify the most accurate PCM models from a qualitative and quantitative point of view by providing explanations to the different trends obtained. To provide this ranking, some of the most common metrics used to measure accuracy are used, namely, the root mean square error (RMSE) and the coefficient of determination $\left(\mathrm{R}^{2}\right)$, both in the absence and in presence of PCM.

\section{Methodology}

In this section, the experimental equipment designed to make a comparison between the predictions of the three dynamic simulation tools considered, namely TRNSYS, EnergyPlus and IDA ICE, is presented.

\section{Experimental equipment}

The experimental measurements were made on a reference STB and another STB, identical to the previous one, with a PCM panel placed on a portion of the floor. Figure 1 shows the STB employed raised compared to the basement.

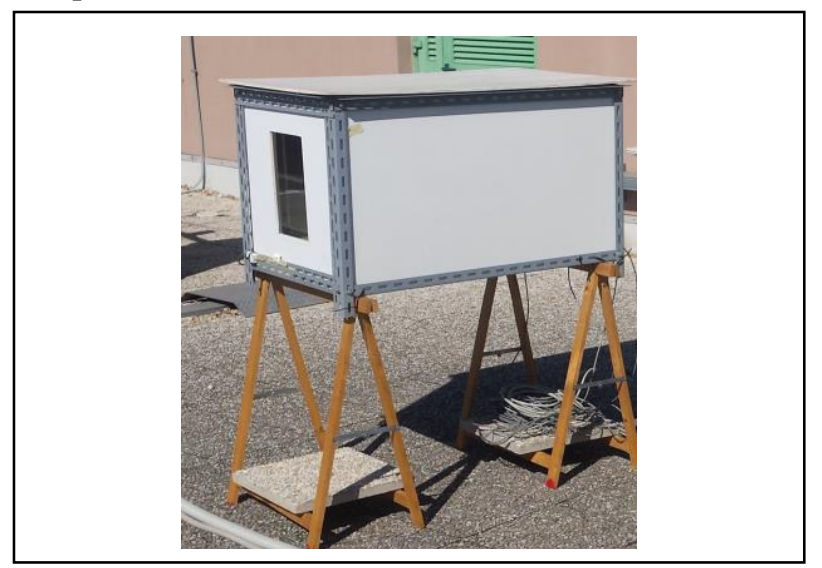

Figure 1: Solar test box.

All the external walls of both STBs are insulated, except the southern wall where a windowed surface is placed. Since the opaque walls are almost adiabatic, then the solar heat gains transmitted through the windowed surface represents the highest heat flux in the cavity. This experimental equipment was previously employed for a comparative analysis of the thermal and lighting performance of innovative transparent materials
(Cornaro et al., 2015) and to validate a PCM tool in IDA ICE environment (Cornaro et al., 2017). The STBs are located at the University of Rome Tor Vergata and, by means of a weather station, the external air humidity and temperature (Rotronic Hygroclip2 sensor, $\pm 0.1^{\circ} \mathrm{C}, \pm 0.8$ $\%$ ), normal direct solar radiation (Kipp and Zonen $\mathrm{CH} 1$ pyrheliometer mounted on a $2 \mathrm{AP}$ sun tracker, $\pm 2 \%$ ), horizontal diffuse solar radiation (Kipp and Zonen CM21 shielded pyranometer mounted on a 2AP sun tracker, $\pm 3 \%$ a $1000 \mathrm{~W} / \mathrm{m}^{2}$ ) and wind speed intensity and direction (model 7911 anemometer, $\pm 1 \mathrm{~m} / \mathrm{s}, \pm 7^{\circ}$ ) are continuously detected. Starting from these measurements, other climatic data were generated by applying proper dynamic calculation models, such as for the sky temperature (Daguenet model), solar radiation on the inclined plane (Perez model for the diffuse component) and the basement surface temperature set equal to the external air temperature. The external and internal dimensions are respectively $1.00 \times 0.550 \times 0.600$ $\mathrm{m}$ and $0.872 \times 0.374 \times 0.424 \mathrm{~m}$, while the clear double glazed pane occupies $0.06 \mathrm{~m}^{2}$ with dimensions $0.30 \times 0.20 \mathrm{~m}$, has a solar heat gain coefficient of 0.76 and a normal solar transmission coefficient of 0.70 . The PCM panel installed on the floor is the CSM (compact storage modules) produced by Rubitherm Technologies $\mathrm{GmbH}$. This module consists of an aluminium case of $0.450 \times 0.300 \times 0.015 \mathrm{~m}$, coated with an anticorrosive material and filled with $2 \mathrm{~kg}$ of macroencapsulated inorganic PCM SP21E. It is characterized by an overall latent heat storage capacity of $129 \mathrm{~kJ} / \mathrm{kg}$ with a moderate hysteresis: a fusion temperature range of between $19^{\circ} \mathrm{C}$ and $23{ }^{\circ} \mathrm{C}$ with a peak of $54 \mathrm{~kJ} / \mathrm{kgK}$ at $22^{\circ} \mathrm{C}$, and a solidification temperature range of between $17^{\circ} \mathrm{C}$ and 20 ${ }^{\circ} \mathrm{C}$ with a peak of $60 \mathrm{~kJ} / \mathrm{kgK}$ at $20^{\circ} \mathrm{C}$. Table 1 reports the wall stratigraphies, and their thicknesses and thermal trasmittances $U$ calculated considering $0.04 \mathrm{~m}^{2} \mathrm{~K} / \mathrm{W}$ and $0.13 \mathrm{~m}^{2} \mathrm{~K} / \mathrm{W}$ of external and internal surface thermal resistances, respectively.

Table 1: STB Stratigraphies (PW:Plywood,

Ins:Insulation, Gl:glass), thicknesses and thermal trasmittances.

\begin{tabular}{|c|c|c|c|c|c|}
\hline $\begin{array}{c}\text { STB } \\
\text { Envelope }\end{array}$ & \multicolumn{4}{|c|}{$\begin{array}{c}\text { Stratigraphies } \\
\text { (from the outside to the inside) } \\
\text { Thicknesses (mm) }\end{array}$} & $\begin{array}{c}\mathbf{U} \\
\mathbf{W} / \mathbf{m}^{2} \mathbf{K}\end{array}$ \\
\hline \multirow{2}{*}{$\begin{array}{l}\text { External } \\
\text { walls }\end{array}$} & $P W$ & Ins & & & \multirow{2}{*}{0.280} \\
\hline & 8 & 80 & & & \\
\hline \multirow{2}{*}{$\begin{array}{c}\text { Southern } \\
\text { wall }\end{array}$} & $P W$ & $G l$ & Air & $G l$ & \multirow{2}{*}{1.345} \\
\hline & 8 & 4 & 12 & 4 & \\
\hline \multirow{2}{*}{ Window } & $G l$ & Air & $G l$ & & \multirow{2}{*}{2.712} \\
\hline & 4 & 12 & 4 & & \\
\hline \multirow{2}{*}{$\begin{array}{l}\text { Floor } \\
\text { ref-STB }\end{array}$} & $P W$ & Ins & & & \multirow{2}{*}{0.280} \\
\hline & 8 & 80 & & & \\
\hline \multirow{2}{*}{$\begin{array}{c}\text { Floor } \\
\text { PCM-STB }\end{array}$} & $P W$ & Ins & $P C M$ & & \multirow{2}{*}{0.279} \\
\hline & 8 & 80 & 10.2 & & \\
\hline
\end{tabular}

The thermophysical (density $\rho$, thermal conductivity $\lambda$ and specific heat capacity $c_{p}$ ) properties and longwave and shortwave optical properties (emissivity $\varepsilon$ and absorptivity $\alpha$ ) of the materials are listed in Table 2 .

The external surface convective heat transfer coefficient is set to $20 \mathrm{~W} / \mathrm{m}^{2} \mathrm{~K}$, while on the internal surface 
dynamic calculation models are used. A value of $0.5 \mathrm{~h}^{-1}$ is employed for the infiltration flow rate.

Table 2: Thermophysical and optical properties

\begin{tabular}{|c|c|c|c|c|c|}
\hline Materials & $\begin{array}{c}\boldsymbol{\rho} \\
\mathbf{k g} / \mathbf{m}^{\mathbf{3}}\end{array}$ & $\begin{array}{c}\boldsymbol{\lambda} \\
\mathbf{W} / \mathbf{m K}\end{array}$ & $\begin{array}{c}\mathbf{c}_{\mathbf{p}} \\
\mathbf{J} / \mathbf{k g K}\end{array}$ & $\begin{array}{c}\boldsymbol{\varepsilon} \\
-\end{array}$ & $\begin{array}{c}\boldsymbol{\alpha} \\
-\end{array}$ \\
\hline Plywood & 545 & 0.120 & 1215 & 0.900 & 0.200 \\
\hline Insulation & 36 & 0.024 & 1453 & 0.900 & 0.500 \\
\hline Glass & 2400 & 1.000 & 800 & 0.837 & 0.177 \\
\hline Air & 1.2 & 0.0241 & 1005 & - & - \\
\hline PCM & 1450 & 0.600 & 2000 & 0.600 & 0.400 \\
\hline
\end{tabular}

Each STB is instrumented by TT500 thermistors $\left( \pm 0.2^{\circ} \mathrm{C}\right)$ to measure the internal air temperature, external and internal surface temperature of the glass, and internal surface temperature of the floor. Further details on the measurement station and sensors location can be found within previous works (Cornaro et al., 2015; Cornaro et al., 2017).

\section{Heat transfer models of the BPS tools}

The BPS tools can be classified as general-purpose or special-purpose simulation tools. By means of the first typology of tools, the users can define proper mathematical models making them more flexible with the disadvantage of difficulty of use and low execution speed. Instead, in the second typology of tools, different predefined standard simulation problems are available and permit to obtain a high execution speed, with the disadvantage of lower flexibility in the simulation of non-standard problems. Consequently, the two typologies differ mainly for source code access and modification mode, and control simulation capability. TRNSYS and IDA ICE fall into the first typology, while EnergyPlus in the second one. TRNSYS, developed at the Solar Energy Laboratory of the University of Wisconsin-Madison, is a flexible transient system simulation program for complex systems with a modular structure, characterised by the division of a problem into a series of smaller components. In addition, new models can be compiled into new components and introduced in the TRNSYS library. TRNBuild 2.0 (TRANSSOLAR energietechnic GmbH, 2012) is a link interface with Type 56 of TRNSYS for the geometric, thermal and optical definition of a specific building. IDA ICE is a flexible whole-building performance simulation tool, developed at Department of Building Sciences (Stockholm), which works with symbolic equations instead of variable assignments, and therefore it is relatively easy to extend the existing modelling functionality. EnergyPlus, developed by the U.S. Department of Energy, is a whole building energy simulation program based on a modular structure that has shown a continuous enhancement in the possibility of adding and validating new models. DesignBuilder 5.5 (DesignBuilder Software Ltd, 2019) provides an easy-touse interface to develop building designs from concept through to completion. However, the mathematical models employed to predict the conductive, convective and longwave and shortwave radiative heat transfer between the external envelope and the indoor and outdoor environments represent the main differences between the BPS tools (Solar Energy Laboratory, University of Wisconsin-Madison, 2012; U.S. Department of Energy, 2012; Bring et al., 1999). A list and a summary of the models employed by the considered BPS tools are reported in Table 3. On the external surface, the thermal balance equation is similar in the three tools:

- the total absorbed solar radiation on the inclined surface is computed identically by the three BPS tools as a function of the azimuth, inclination and incidence angles, and wall absorptivity;

- the longwave radiative heat transfer with the outdoor environment is modelled with the grey body model that requires fictive sky and basement temperatures, and the emissivities and view factors of walls. EnergyPlus considers also a fictive longwave thermal exchange with the air to correct the hypothesis of the sky as a black body;

- the convective heat transfer coefficient can be maintained constant or variable in EnergyPlus and TRNSYS. EnergyPlus contains a wide availability of algorithms that consider natural, mixed and forced convective models as a function of the wind speed, wall inclination and temperature difference between air and wall surface. IDA ICE uses a dynamic model as a function of the wind speed.

As regards the conductive heat transfer in opaque walls, TRNSYS uses transfer function or response factors by considering the wall as a black box with considers the thermal history of the wall by means of a time series parameter. The coefficients of the time series are evaluated using the z-transfer function. To simulate the heat conduction into EnergyPlus, two different approaches are available: the first one based on the conduction transfer functions calculated with the Laplace transformations and the second one based on the conduction implicit finite difference solution algorithm. The choice of the algorithm depends on the presence of a PCM layer in the envelope that requires the use of the second approach. IDA ICE employs an explicit finite difference method based on an RC model. The parameters of the RC network are calculated by an optimization subroutine, which compares the model behaviour to analytical solutions obtained for simple harmonic boundary conditions and calculates the sum of the squares of the deviations.

A similar detailed optical and thermal window model is used by TRNSYS and EnergyPlus, by using output data imported from the WINDOW 7.6 program developed by Lawrence Berkeley Laboratory, USA (2017). In the program WINDOW, the detailed calculation of reflection between the individual panes and the absorption and transmission of each pane is performed hemispherically for diffuse radiation and in steps of $10^{\circ}$ incidence angle for direct solar radiation. The detailed window model calculates transmission, reflection and absorption of solar radiation in detail for windows with up to six panes. For each glass pane, the resulting temperature is calculated considering transmission, 
absorption and reflection of incoming direct and diffuse solar radiation, diffuse shortwave radiation being reflected from the walls of the air node or an internal shading device, convective, conductive and long-wave radiative heat transfer between the individual panes and with the indoor and outdoor environment. Each glazing absorbs and reflects a part of the incoming solar radiation depending on the glazing material and the incidence angle. The IDA ICE window model divides the solar radiation entering through a window into two parts, directly transmitted radiation, and distributed as shortwave radiation to the zone, and radiation first absorbed and then released to the zone as longwave radiation and convection. The direct and diffuse radiation are reduced, respectively, by means a factor that changes as a function of the angle of incidence, and a constant hemispherical factor. Consequently, TRNSYS and EnergyPlus allow users to consider the directionality effects of the transmitted radiation, while in IDA ICE a constant hemispheric or normal value of the optical properties is required. Similarly to the external surface, the three tools calculate the terms of the thermal balance equation on the internal surface with the most sophisticated models. However, only TRNSYS foresees a detailed treatment of shortwave beam radiation distribution entering a zone through external windows, by calculating for each time step the sunlit factor matrices generated by TRNBuild.

Table 3: Methods employed by BPS tools to model the heat transfer processes through a building envelope.

\begin{tabular}{|c|c|c|c|}
\hline Heat transfer approach & TRNSYS & EnergyPlus & IDA ICE \\
\hline \multicolumn{4}{|c|}{ Heat transfer between the building envelope and outdoor environment } \\
\hline Convective with air & $\begin{array}{c}\text { Based on a constant or variable } \\
\text { convective heat transfer } \\
\text { coefficient }\end{array}$ & $\begin{array}{l}\text { Different algorithms based on } \\
\text { a constant or variable } \\
\text { convective heat transfer } \\
\text { coefficient considering natural, } \\
\text { mixed or forced convection }\end{array}$ & $\begin{array}{l}\text { Based on a variable convective } \\
\text { heat transfer coefficient }\end{array}$ \\
\hline $\begin{array}{c}\text { Shortwave radiative absorbed } \\
\text { by opaque walls }\end{array}$ & $\begin{array}{l}\text { Model based on constant } \\
\text { optical properties }\end{array}$ & $\begin{array}{l}\text { Model based on constant } \\
\text { optical properties }\end{array}$ & $\begin{array}{l}\text { Model based on constant } \\
\text { optical properties }\end{array}$ \\
\hline $\begin{array}{l}\text { Longwave radiative with the } \\
\text { sky, basement and air }\end{array}$ & $\begin{array}{l}\text { Model based on the thermal } \\
\text { exchange between a grey } \\
\text { surface and a black body at a } \\
\text { fictive temperature. Fictive air } \\
\text { temperature excluded }\end{array}$ & $\begin{array}{l}\text { Model based on the thermal } \\
\text { exchange between a grey } \\
\text { surface and a black body at a } \\
\text { fictive temperature. Fictive air } \\
\text { temperature included }\end{array}$ & $\begin{array}{l}\text { Model based on the thermal } \\
\text { exchange between the grey } \\
\text { surface and a black body at a } \\
\text { fictive temperature. Fictive air } \\
\text { temperature excluded }\end{array}$ \\
\hline $\begin{array}{l}\text { Conductive in the opaque and } \\
\text { transparent wall }\end{array}$ & Transfer Function Method & $\begin{array}{l}\text { Conduction transfer functions } \\
\text { or conduction implicit finite } \\
\text { difference solution algorithm }\end{array}$ & $\begin{array}{c}\text { THETA-method integrator, RC } \\
\text { network model based on an } \\
\text { explicit finite difference } \\
\text { method }\end{array}$ \\
\hline $\begin{array}{l}\text { Optical and thermal } \\
\text { transmission in transparent } \\
\text { walls }\end{array}$ & $\begin{array}{c}\text { Complex thermal and optical } \\
\text { model, and optical properties } \\
\text { dependent on the incidence } \\
\text { angle }\end{array}$ & $\begin{array}{c}\text { Complex thermal and optical } \\
\text { model, and optical properties } \\
\text { dependent on the incidence } \\
\text { angle. }\end{array}$ & $\begin{array}{l}\text { Simplified model based on the } \\
\text { computation of the directly } \\
\text { transmitted radiation and } \\
\text { radiation first absorbed and } \\
\text { then released as longwave } \\
\text { radiation and convection }\end{array}$ \\
\hline \multicolumn{4}{|c|}{ Heat transfer between the building envelope and indoor environment } \\
\hline Convective with air & $\begin{array}{c}\text { Based on a constant or variable } \\
\text { heat transfer coefficient } \\
\text { evaluated considering natural } \\
\text { convection }\end{array}$ & $\begin{array}{l}\text { Different algorithms based on } \\
\text { a constant or variable } \\
\text { convective heat transfer } \\
\text { coefficient }\end{array}$ & $\begin{array}{c}\text { Based on a variable heat } \\
\text { transfer coefficient evaluated } \\
\text { considering natural convection }\end{array}$ \\
\hline $\begin{array}{l}\text { Heat flux caused by direct } \\
\text { solar radiation originating } \\
\text { from external windows }\end{array}$ & $\begin{array}{l}\text { Method of the sunlit factor } \\
\text { matrices }\end{array}$ & $\begin{array}{l}\text { Shadowing routines to } \\
\text { calculate the internal surface } \\
\text { area irradiated by the beam } \\
\text { solar radiation projected on the } \\
\text { external window }\end{array}$ & $\begin{array}{l}\text { It is considered diffuse. } \\
\text { Net absorption method based } \\
\text { on the shortwave net } \\
\text { absorption matrix }\end{array}$ \\
\hline $\begin{array}{l}\text { Heat flux caused by diffuse } \\
\text { solar radiation originating } \\
\text { from external windows }\end{array}$ & Solar Gebhart matrix method & $\begin{array}{l}\text { Method based on transmission- } \\
\text { absorption weighted area } \\
\text { factors }\end{array}$ & $\begin{array}{l}\text { Net absorption method based } \\
\text { on the shortwave net } \\
\text { absorption matrix }\end{array}$ \\
\hline $\begin{array}{l}\text { Longwave radiative between } \\
\text { internal walls }\end{array}$ & $\begin{array}{l}\text { Longwave Gebhart matrix } \\
\text { method }\end{array}$ & $\begin{array}{l}\text { Grey interchange model of } \\
\text { Hottel based on the matrix of } \\
\text { exchange coefficients }\end{array}$ & $\begin{array}{c}\text { Net radiation method based on } \\
\text { the longwave net absorption } \\
\text { matrix }\end{array}$ \\
\hline \multicolumn{4}{|c|}{ Heat transfer through a phase change material } \\
\hline $\begin{array}{l}\text { Latent heat storage in the } \\
\text { phase change material }\end{array}$ & Lumped method & Enthalpy method & $\begin{array}{c}\text { Enthalpy method with } \\
\text { hysteresis }\end{array}$ \\
\hline
\end{tabular}


The current sunlit fraction of surfaces is determined by bilinear interpolation of the four nearest centre points with respect to the actual position of the sun. In addition, it defines a so-called solar to air factor to consider the fraction of solar radiation entering an air node through external windows which is immediately transferred as a convective gain to the internal air. Similarly, EnergyPlus uses shadowing routines to calculate an overlap area, namely the irradiated area by the beam solar radiation of the internal surfaces projected on the exterior window. The overlap areas for a particular exterior window depend on the sun position, the geometry of the window, the geometry of the interior surfaces, and the location of the window with respect to the interior surfaces. For the purposes of the surface heat balance calculation, any beam solar radiation absorbed by a surface is assumed to be uniformly distributed over the surface. Finally, IDA ICE presents the least accurate model by considering the direct solar radiation as diffuse. As regards the diffuse solar radiation entering through the window, EnergyPlus is the least accurate since employs a weighted distribution on the internal walls of the zone dependent on the area and absorptivity of the surfaces. Instead, the other tools treat the diffuse solar radiation, in an analogous manner to the longwave radiation, by calculating the relative solar matrices. The longwave radiative heat transfer models are very similar and based on the calculation of proper matrices, containing optical and geometric properties of the walls of the zone. For the internal convective heat transfer coefficient, a sole natural convective model is used IDA ICE, while EnergyPlus and TRNSYS are very flexible, by allowing users the use of different options (constant or variable) and models, which are a function of the wall inclination and temperature difference between air and wall surface.

Owing to the increasing development of innovative building components, the BPS tools receive constantly regular updates and extension of modelling capabilities without to change the concepts and basic software architecture. In fact, the materials initially considered in the tool development are characterized by constant thermophysical and optical properties by varying the space and the time. In the last decades, the diffusion of researches on PCMs has led to the introduction in BPS tools of predictive models of the latent heat storage in a PCM wall. The mathematical models used to describe the latent heat storage in a PCM are reported in Table 3 at the bottom.

Accordingly, TRNSYS has incorporated a very simple PCM model (Type 1270), designed to interact with Type56 (building model) and can model a PCM located in any position within a wall that separates two thermal zones (TESSLibs 17, 2010). Type1270 implements a lumped method coupled with the quasi-heat source method to model a pure PCM, which undergoes a phase change at a constant temperature by storing or releasing the latent heat. The thermophysical properties are considered constant in the two phases and independent of temperature. When the PCM material is fully solidified, the temperature at the end of a time step is given by Eq. (1):

$$
\mathrm{T}_{\mathrm{f}}=\mathrm{T}_{\mathrm{i}}+\left(\frac{\mathrm{q}_{1}+\mathrm{q}_{2}}{\mathrm{~m}_{\mathrm{PCM}} \mathrm{c}_{\mathrm{p}, \mathrm{s}}}\right)
$$

when the PCM material is fully melted, the temperature at the end of a time step is given by Eq.(2):

$$
\mathrm{T}_{\mathrm{f}}=\mathrm{T}_{\mathrm{i}}+\left(\frac{\mathrm{q}_{1}+\mathrm{q}_{2}}{\mathrm{~m}_{\mathrm{PCM} \mathrm{c}_{\mathrm{p}, \mathrm{l}}}}\right)
$$

where, $\mathrm{q}_{1}$ and $\mathrm{q}_{2}$ are the powers entering the PCM from the adjacent wall layers, $\mathrm{m}_{\mathrm{PCM}}$ is the PCM mass and $\mathrm{c}_{\mathrm{p}, \mathrm{s}}$ and $c_{p, 1}$ are the specific heat capacities at the solid and liquid state of the PCM respectively. When the PCM material is in the transition state, the final and initial temperatures are equal as the phase change occurs at a constant temperature, and Type1270 simply records the energy stored or released. If the energy absorbed by the PCM during a particular time step exceeds the PCM latent storage capacity, Type1270 applies the remaining energy to a temperature change in the liquid phase using Eq. (2). Likewise, if the PCM is giving more energy than that stored to the surrounding wall layers in a particular time step, Type1270 applies the remaining energy to a temperature change in the solid phase using Eq. (1). To use Type 1270 in an external wall, the standard connections of Type 1270 with Type 56 was modified and the calculation of the power entering the PCM layer from the outdoor environment $\mathrm{q}_{1}$ was analytically implemented. In summary, Type 1270 requires only the total latent heat and PCM phase change temperature, which was set to $21^{\circ} \mathrm{C}$, the mean value between the melting and solidification peak temperatures.

A more sophisticated model was incorporated in EnergyPlus, which considers a conduction finite difference solution algorithm with an enthalpytemperature function to account for phase change accurately (Tabares-Velasco et al., 2012). The tool in its version 8.6 requires a sole enthalpy-temperature curve to be used both in the fusion and solidification process to detect an equivalent specific heat capacity at each time step. The users can choose to set the fusion, solidification or a mean enthalpy-temperature curve. In this work, the mean curve was selected. The resulting model is a modified version of the enthalpy method. This new algorithm also includes a variable thermal conductivity with the temperature. Eq. (3) and enthalpytemperature function are generated for each node of the PCM material. The node temperatures and enthalpies are updated after each iteration and are used to obtain the variation of the specific heat $c_{p}$. The $c_{p}$ is formulated by Eq. (4).

$$
\begin{aligned}
\frac{\rho C p \Delta x\left(T_{i}^{n+1}-T_{i}^{n}\right)}{\Delta t} & =\frac{k\left(T_{i-1}^{n+1}-T_{i}^{n+1}\right)}{\Delta x}+\frac{k\left(T_{i+1}^{n+1}-T_{i}^{n+1}\right)}{\Delta x} \\
C_{P} & =\frac{\left(H_{i}^{n+1}-H_{i}^{n}\right)}{T_{i}^{n+1}-T_{i}^{n}}
\end{aligned}
$$

Where, $c_{p}$ is the specific heat capacity, $\Delta t$ time step, $\Delta x$ $\mathrm{B} / \mathrm{M}, \mathrm{M}$ number of parts that the region $0 \leq \mathrm{x} \leq \mathrm{B}$ is divided, i spatial discretization, and $\mathrm{n}$ time discretization. Until recently, IDA-ICE had not supported a direct modelling of PCM layers, so EQUA Simulation AB has 
developed an add-in for IDA ICE, called "PCMWALL". In IDA ICE, the modelling of PCM is based on the enthalpy method, which requires the enthalpytemperature relationship both in the heating and in the cooling process to take into account the hysteresis phenomenon. The enthalpy is not only dependent on the current state but also on the previous state, as it captures the hysteresis physics present between the fusion and solidification processes.

\section{Results}

Comparison between the results of BPS tools was made during two experimental campaigns: in September with clear sky conditions and in December with one day in cloudy sky condition and the other days with a clear sky. The warm period, as shown in Figure 2 on the top is characterized by high external air temperatures Tae and by a peak of solar radiation incident on the southern window Gs and horizontal plane Gh that reached about $800 \mathrm{~W} / \mathrm{m}^{2}$. In the cold period, as shown in Figure 3 on the top, the external air temperature and fictive sky temperature Tsky are low, while the peak of the solar radiation on the southern window increases above 900 $\mathrm{W} / \mathrm{m}^{2}$. Overall, in December, the solar energy incident is lower than that in September.

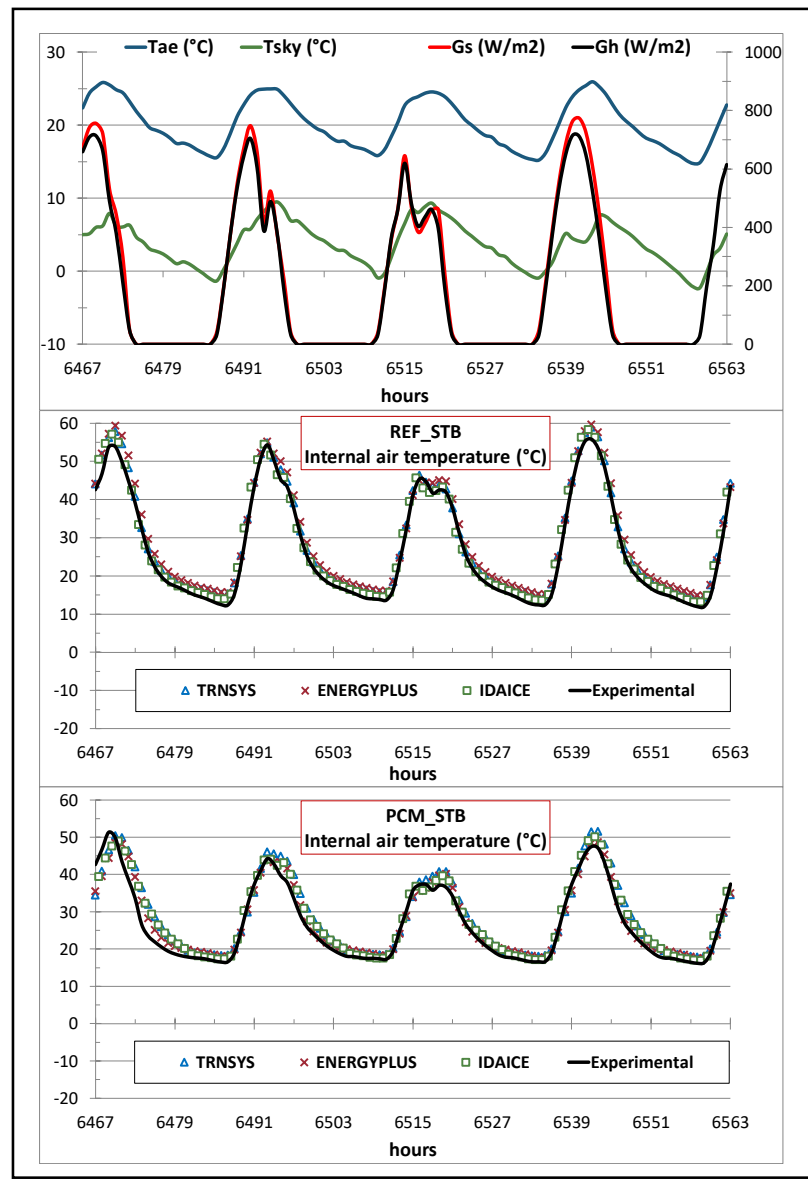

Figure 2: Comparison of experimental and simulated internal air temperature in September. At the top: outdoor weather conditions; at the centre: reference STB; at the bottom: PCM STB.

Figures 2 and 3 show, for the two experimental campaigns, the comparison between experimental and simulated internal air temperature trends inside the reference STB and PCM STB, respectively at the centre and at the bottom.

Generally, both in the absence and presence of PCM, the BPS tools show an excellent agreement with experimental trends.

For reference STB, the results are particularly overlapped with each other and with experimental trends. The slight deviations highlighted during the peak hours are to be attributed to the different approach used to distribute the solar radiation into the STB, while the differences during the night are owing to the different model used to calculate the variable internal convective heat transfer coefficient and to the different conductive heat transfer model in the walls.

The PCM placed on the floor allows the STB to dampen the temperature fluctuation both in summer and winter period. In particular, the thermal excursion, the difference between the maximum and minimum temperature, is reduced from $44^{\circ} \mathrm{C}$ to $35^{\circ} \mathrm{C}$ and from 49 ${ }^{\circ} \mathrm{C}$ to $36^{\circ} \mathrm{C}$ respectively in September and December. The simulated surface floor temperature establishes that in September the PCM panel is prevalently in the liquid phase and a solidification process occurs during the late evening of each day when the external air temperature decreases and solar radiation is nil. This process does not complete because the cooling effect produced by the external longwave radiation and convective is not enough, and the PCM panel recovers the liquid phase in the morning. Instead, in December in the cloudy day, the PCM panel is always solid, while in the other days, the PCM panel stores the solar radiation passing through the window incident on the floor allowing a complete phase change from the solid phase to the liquid phase. This process starts in the late morning and ends in the late afternoon when the PCM return in solid phase releasing all the latent heat stored.

Overall, in the cold period, the weather conditions and the phase change temperature allows exploiting the phase change better than the warm season. Consequently, the major deviations between the three BPS tools can be mostly appreciated in December owing to the different hypothesis formulated in the model definition. In particular, the effect of the constant melting temperature of the TRNSYS model can be highlighted by observing the higher internal air temperature during the solidification process and the lower internal air temperature during the fusion process. The floor surface temperature is constrained to remain constant, by influencing the internal air temperature, even when during the fusion process the floor temperature should be increased and during the solidification process should be decreased. Since the latent heat stored and released only depends on the thermal power quantity incident the floor, at the end of the phase change process all the three tools are again overlapped.

Instead, the EnergyPlus model tends to provide lower air internal temperature than the experimental ones during 
the solidification process because a unique enthalpytemperature function for the heating and cooling process was introduced. In this way, if the sole fusion curve or a mean curve is set, the material completes the solidification process before owing to the higher value of phase change temperatures. The deviation to the experimental trend depends on the difference between the solidification and fusion latent heat, namely on the hysteresis phenomenon.

Finally, the enthalpy hysteresis model of IDA ICE allows obtaining the best prediction of the thermal behaviour of the PCM STB from a qualitative point of view. Only during the night before the cloudy day, the simulated trend presents higher differences compared to the experimental trend. This is owing to the non-correct evaluation of the heat dispersed in the outdoor environment through the floor. By comparing the external surface heat flux of the floor computed by the three tools, it emerges that EnergyPlus estimates a greater heat dispersed in the outdoor environment. This leads to a quicker solidification process compared to that foreseen by IDA ICE and TRNSYS. This difference can be imputed at the difference algorithm used for the calculation of basement temperature for the longwave radiative exchange.

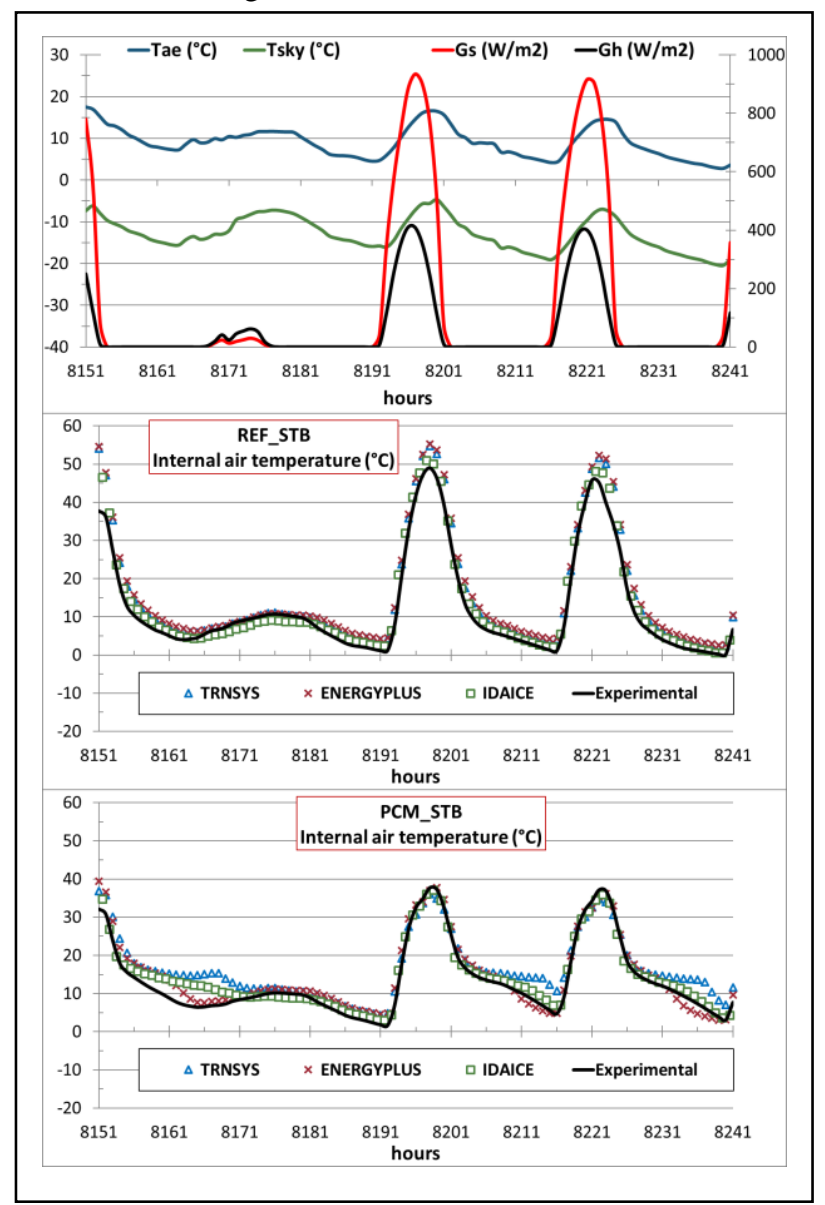

Figure 3: Comparison of experimental and simulated internal air temperature in December. At the top: outdoor weather conditions; at the centre: reference STB; at the bottom: PCM STB.
Table 4 reports the root mean square error RMSE and the coefficient of determination $\mathrm{R}^{2}$ in all cases considered. For the reference STB, the minimum RMSE and maximum $\mathrm{R}^{2}$ in September are obtained by using TRNSYS, while in December by using IDA ICE. Overall, EnergyPlus leads to the least accurate results in the absence of PCM. Instead, for the PCM STB, IDA ICE presents the lowest deviation compared to the experimental results both in warm and cold period owing to the hysteresis phenomenon modelling. Despite this, EnergyPlus accuracy is almost comparable with that of IDA ICE. Finally, Type 1270 of TRNSYS leads to the worst accuracy. However, although it does not allow temperature trends during the phase change to be predicted exactly, it allows the overall latent heat stored and released to be computed enough accurately by requiring only a few thermophysical data and the lowest computational cost.

Table 4: RMSE and $R^{2}$ between measured and simulated internal air temperature for September and December period.

\begin{tabular}{|c|c|c|c|}
\hline & TRNSYS & ENERGYPLUS & IDA ICE \\
\hline \multicolumn{4}{|c|}{ September REF_STB } \\
\hline RMSE $\left({ }^{\circ} \mathrm{C}\right)$ & 2.027 & 2.985 & 2.043 \\
\hline $\mathrm{R}^{2}$ & 0.997 & 0.992 & 0.986 \\
\hline \multicolumn{4}{|c|}{ December REF_STB } \\
\hline RMSE $\left({ }^{\circ} \mathrm{C}\right)$ & 3.928 & 4.635 & 2.374 \\
\hline $\mathrm{R}^{2}$ & 0.983 & 0.979 & 0.984 \\
\hline \multicolumn{4}{|c|}{ September PCM_STB } \\
\hline RMSE $\left({ }^{\circ} \mathrm{C}\right)$ & 3.590 & 2.433 & 2.652 \\
\hline $\mathrm{R}^{2}$ & 0.923 & 0.953 & 0.960 \\
\hline \multicolumn{5}{|c|}{ December PCM_STB } \\
\hline RMSE $\left({ }^{\circ} \mathrm{C}\right)$ & 4.152 & 2.425 & 2.196 \\
\hline $\mathrm{R}^{2}$ & 0.934 & 0.960 & 0.968 \\
\hline
\end{tabular}

\section{Conclusions}

The paper aimed to provide a comparison between the most popular BPS tools by developing an experimental verification that employs a conventional test box and a PCM-based test box in two characteristic summer and winter periods. For this issue, a comprehensive examination of the mathematical models used by the BPS tools considered was carried out. TRNSYS can be considered the most sophisticated in the modelling of solar radiation passing through the window since it considers variable optical properties with incidence angle and in terms of treatment of direct and diffuse solar radiation distribution into a zone. Contrarily, IDA ICE does not take into account the directionality effects of direct solar radiation, while EnergyPlus is the least accurate from a point of view of diffuse solar radiation modelling into a thermal zone. However, IDA ICE and EnergyPlus contain PCM models much more accurate than that of TRNSYS.

Overall, these considerations find confirmation in the experimental investigation made:

- for the reference STB, TRNSYS leads to the best prediction in September, when the directionality effects of the solar radiation through the windowed wall are very incisive in the calculation of the 
thermal response of the zone owing to the high incident angle caused by the high sun elevation angle that produces a strong variation of the glass optical properties;

- for the PCM STB, IDA ICE turned out the most accurate tool since, owing to the small dimensions of the STB, the latent storage phenomenon is predominant, compared the other heat transfer mechanisms, in the determination of the internal air temperature.

Finally, the research has provided, by means a quantitative analysis, a ranking between the BPS tools, by evaluating RMSE and $\mathrm{R}^{2}$ for the STB devoid of PCM and that including the PCM panel.

\section{Acknowledgement}

This research has been carried out within the "Renovation of existing buildings in NZEB vision (nearly Zero Energy Buildings)" Project of National Interest (Progetto di Ricerca di Interesse Nazionale PRIN) funded by the Italian Ministry of Education, Universities and Research (MIUR).

\section{References}

Building Technologies Office of U.S. Department of Energy's (DOE) Building Technologies Office (BTO) (2016). EnergyPlus 8.6. https://energyplus.net (accessed on 07 February 2019).

Bring, A., Sahlin P., Vuolle M. (1999). Models for Building Indoor Climate and Energy Simulation, A Report of IEA SHC Task 22: Building Energy Analysis Tools, Subtask B: Model Documentation.

Cornaro, C., Bucci, F., Pierro, M., Bonadonna, M. E., and Siniscalco, G. (2015). A new method for the thermal characterization of transparent and semitransparent materials using outdoor measurements and dynamic simulation. Energy and Buildings 104, 57-64.

Cornaro, C., Pierro, M., Puggioni, V. A., and Roncarati, D. (2017). Outdoor Characterization of Phase Change Materials and Assessment of Their Energy Saving Potential to Reach NZEB. Buildings 7(3), 55.

DesignBuilder Software Ltd version 5.5.0 (2019). https://designbuilder.co.uk (accessed on 07 February 2019).

Equa Simulation AB (2018). IDA Indoor Climate and Energy 4.8. https://www.equa.se/en/ (accessed on 07 February 2019).

Harish V.S.K.V., Kumar A. (2016). A review on modeling and simulation of building energy systems. Renewable and Sustainable Energy Reviews 56, 1272-1292.

International Energy Agency (2017). Global status report 2017, Towards a zero-emission, efficient, and resilient buildings and construction sector.
Jayalath, A., Aye, L., Mendis, P., and Ngo, T. (2016). Effects of phase change material roof layers on thermal performance of a residential building in Melbourne and Sydney. Energy and Buildings 121, 152-158.

Lawrence Berkeley National Laboratory, USA (2017), WINDOW 7.6. https://windows.lbl.gov/software/window (accessed on 07 February 2019).

Mazzeo, D., Oliveti, G., and Arcuri, N. (2017). A method for thermal dimensioning and for energy behavior evaluation of a building envelope PCM layer by using the characteristic days. Energies, $10(5), 659$.

Mazzeo, D., and Oliveti, G. (2018). Thermal field and heat storage in a cyclic phase change process caused by several moving melting and solidification interfaces in the layer. International Journal of Thermal Sciences 129, 462-488.

Panayiotou, G.P., Kalogirou, S. A., and Tassou, S. A. (2016). Evaluation of the application of Phase Change Materials (PCM) on the envelope of a typical dwelling in the Mediterranean region. Renewable Energy 97, 24-32.

Rubitherm Technologies GmbH, Imhoffweg 6, 12307 Berlin (Germany). https://www.rubitherm.eu/ (Accessed 07 February 2019).

Saffari M., de Gracia A., Ushak S., Cabeza L. F (2017). Passive cooling of buildings with phase change materials using whole-building energy simulation tools: A review. Renewable and Sustainable Energy Reviews 80, 1239-1255.

Solar Energy Laboratory, University of WisconsinMadison (2012). TRNSYS 17 Documentation, Volume 5, Multi zone Building modeling with Type56 and TRNBuild.

Tabares-Velasco, P.C., Christensen, C., and Bianchi, M. (2012). Verification and validation of EnergyPlus phase change material model for opaque wall assemblies. Building and Environment 54, 186-196.

TESS - Thermal Energy Systems Specialists (2010), TESSLibs 17, Component Libraries for the TRNSYS Simulation Environment, Volume A3 TESS Component Libraries.

TRANSSOLAR energietechnic GmbH (2012), TRNBuild 2.0, https://transsolar.com/ (accessed on 07 February 2019).

University of Wisconsin (2012). TRNSYS 17: A transien system simulation program. Solar Energy Laboratory. http://www.trnsys.com/ (accessed on 07 February 2019).

U.S. Department of Energy (2012). EnergyPlus ${ }^{\mathrm{TM}}$ Version 8.6 Documentation, Engineering Reference. 